DOI: $10.24234 /$ wisdom.v18i2.491

Galyna HNAT, Ihor HNES, Liubov SOLOVII, Lyudmyla HNES, Volodymyr BABYAK

\title{
SOCIO-ADAPTIVE THINKING OF SEARCHING FOR AN ARCHITECTURAL CONNECTION TO IMPROVE THE LIVES OF STUDENTS WITH SPECIAL PHYSICAL NEEDS AS A SPECIAL KIND OF PHILOSOPHICAL COMMUNICATION
}

\begin{abstract}
An analysis of the modern spiritual situation, particularly the Western world, prompts the idea that a person's place in it is becoming increasingly uncertain and contradictory. This is especially clear in various conflicts arising among people with disabilities because of infrastructure problems in educational institutions. It is evident that disabled people and various categories of mentally and physically weakened people are a very significant part of our society, for which accessible and comfortable conditions of life and rehabilitation should be created. This requirement should be considered among the fundamental, and it should apply too many significant objects of the social infrastructure of modern cities, including their higher educational institutions. The primary purpose is to determine the ways of adapting the architectural environment of higher education institutions to the needs of persons with disabilities. The object of the research is the buildings and structures of higher education institutions. To achieve the goal of our research, we have used an IDEF0 model in achieving social adaptation and improving communication.
\end{abstract}

Keywords: socio-adaptive, physical needs, philosophical communication, architectural environment, persons with disabilities.

Introduction

Historians point out that during the times of Kievan Rus, people with various types of physical limitations were given some attention, treated humanely and mercifully. Such defining principles for the needy took place in the social structure of the state and were supported by the adoption of certain legislative acts. The first official documents, referring to the provision of assistance to those in need, date back to the end of the $10^{\text {th }}$ century, when the Kyiv prince Vladimir Svyatoslavovich by decree of 996, obliged the church to take care of persons with disabilities, orphans and the poor people. The state and socie- ty took care of all those in need for distinguishing separate categories. Therefore, tolerant attitude and help to the disabled were traced in the context of caring for orphans, needy elders and other categories.

For centuries, the policy of many states regarding persons with disabilities has been aimed at one goal - to make them "invisible" and hide from a prejudiced society.

Today, social adaptation of the conditions of individual infrastructures to the needs of people with disabilities is very acute. This also applies to educational institutions, where the philosophy of communication plays a key role.

Communication is a process in which two 
subjects take part, the main content of which becomes spiritual communication, where a person does not turn from a subject into an object of mass influence, and it is especially relevant for students. That philosophy of communication has functioned in proper order, and there must be equal conditions in the infrastructure in which they occur.

A higher educational institution has always been an integral part of the life and development of society. Over the past half-century, universities have radically changed the vector of their development thanks to modernisation and changes in architectural solutions. Today universities have entered a new stage of development, both in the quality of education and in appearance. Many of them are widely known outside their state, and they play the role of a "dominant" object, which has a positive effect on the image of their country.

Accessible education is a key component of a developed society. Modern universities are an institution of professional education. They are a powerful science-intensive and socio-cultural centre that forms the cadre personnel of many public spheres, institutions. Today especially prime requirements are imposed on the level of an integrated organization of all components of its architectural and spacious environment.

At the present stage of its development, the world community is finally ripe to understand that for centuries the environment formed by humankind is uncomfortable for a significant part of the population. The most important requirements for the elements of this environment - the comfort of living and the safety of the environment - are not met in relation to people with disabilities, young children, women with babies and pregnant women, the elderly, injured, who make up most of the population.

From the beginning of the $16^{\text {th }}$ century, the first textbooks for teaching disabled children have appeared in Western Europe, and from the middle of the $17^{\text {th }}$ century, special schools opened. In fact, until the middle of the $20^{\text {th }}$ century, children with psychophysical disabilities studied in isolation from normally developed children in special (correctional) educational institutions.

In most of the countries of Europe and America, the state education systems for children with special educational needs were represented by three models: segregated, integrative, and inclusive.

Today, because of certain physical needs, $15 \%$ of the population cannot get full access to education since the architectural environment of universities is not adapted to the needs of people with disabilities.

The creation of an adapted architectural environment of higher educational institutions, its compliance with the social and functional requirements of promising forms of educational and scientific progress is one of the most essential tasks in the development and modernization of higher education.

At the end of the 1950s, in many developed countries of Western Europe, North America, Canada and Australia, community organizations of people with disabilities have developed guidelines for organizations involved in developing accessibility-sensitive building design standards. According to these recommendations, norms for the design of a barrier-free environment appeared and were officially legalized. The relevance of this work is determined by the need to create an architectural environment of the university, which will be adapted to the needs of people with disabilities.

The main purpose of this article is to determine the ways of adapting the architectural environment of higher education institutions to the needs of persons with disabilities in the context of achieving social adaptation and improving communication.

According to the scientific works of R. Rijst, Y. Baggen, E. Sjoer (2018), D. Froehilich, S. Beausaert, M. Segers (2015) and J. Salmela (2019) on the problems of inclusion of disabled people in society, two equivalent concepts of "integration" and "inclusion" are analyzed. If integration, 
in our opinion, can be interpreted as a person's entry into society, educational institutions, and other groups regularly, then inclusion implies the possibility of full participation of each person in all spheres of activity of these communities. The fundamental difference between these approaches is that in the process of integration, a person adapts to the educational institution. With inclusion, on the contrary, the educational institution creates all the necessary conditions to meet the individual needs of a person.

The problems of forming an adapted architectural space for children and, in particular, young people with disabilities are of great interest in the world (Steen, Manschot, \& de Koning, 2011; Hallgrimsdottir, Wennberg, Svensson, \& Ståhl, 2016; White, Saran, \& Kuper, 2018; Van Dooren, Boshuizen, van Merriënboer, Asselbergs, \& van Dorst, 2014) psychological and pedagogical science. In the research of K. Lisy, J. Campbell, C. Tufanaru, S. Moola, C. Lockwood (2018), E. Boyer, D. Mitgang (1996), R. Segrest (1997), the history of the formation and development of certain areas of special education for schoolchildren with various psychophysical disorders was studied, and ways of architectural optimization of the educational space were proposed.

In the process of writing the article, the authors analyzed a fairly large number of scientific works, as well as legislative and regulatory documents, in which some important aspects of the problem under consideration are directly or indirectly affected.

So, from the point of view of the depth of coverage of the psychophysiological specifics of disabled people, as well as the specific needs of these people caused by it, the previously published works of A. Alrashidi (2010), M. Carmona (2010), A. Azeri Gorji, Z. Shirzad Nazarloo (2018).

The term "barrier-free environment" in the writings of M. Simons, J. Masschelein (2009), R. Segrest (1997) and A. Kamp (2016) is used when referring to people with disabilities. The barrier-free environment presupposes the pres- ence of ramps and sidewalks with a good quality surface, sufficiently wide walkways and driveways, doors and other elements of the architectural environment that facilitate the movement of people with limited mobility. In order to facilitate the understanding of barrier-free space, in the works of P. Vermeersch, A. Heylighen (2012), and L. Francis (2018), the basic principles of this concept have been developed in the context of the architectural organization of higher educational institutions.

Other essential aspects of the problem under consideration, such as social, methodological, urban planning, as well as directly architectural, have not received due attention in the modern theory of architecture. A positive exception is the many works of specialists in sociology, higher education pedagogy, defectology, sanitation and other related and very "remote" areas of knowledge, the leading representatives of which can be considered A. Shahraki, I. Ebrahimzadeh, D. Kashefidoost (2016), M. Kurath (2015) and T. Wirth, N. Frantzeskaki, L. Fuenschilling, L. Coenen (2018). These works are directly related to the topic of our research, as they contain valuable recommendations and instructions for the organization and implementation of various forms of education for people with disabilities.

$$
\begin{gathered}
\text { Philosophy and Psychology } \\
\text { of Disabled People }
\end{gathered}
$$

The most important for students with special needs is the period of adaptation to the conditions of study at the university, the acquisition of a new status, the development of new social roles. Therefore, it isn't so much the content of the education process that is important as the creation of specific psychological and pedagogical conditions that would facilitate the learning process, that is:

- providing a particular approach to students with special needs, which should take into account the specifics of the disease, vices, pathological condition, psychological or so- 
cial problems that a disabled person may encounter in everyday life; the pace of teaching disciplines should be slow enough, flexible, "soft", adapted to the needs of people with disabilities; the study load should be regulated depending on the degree of disability;

- the upbringing process requires more attention, responsibility, understanding and education. People with special needs should be surrounded by love, affection, care. Personal humiliation should not be allowed. It is necessary to take into account their difficulties in learning, help to obtain information by other means (if the usual means are not enough);

- ensuring equal opportunities for participation in university-wide events (provision of transport, auxiliary means, volunteers); raising the general cultural level of students in the direction of fostering a sympathetic, respectful, empathic attitude towards students with special needs, understanding their life problems;

- not to remind or focus on functional limitations, to understand the inner world of a person, to teach a person to live with a disadvantage and at the same time be adequate.

The adaptation process is interdependent. Therefore, not only people with disabilities must develop the qualities of a socialized personality, actively participate in the life of a group, a team, but the group must also go through the path of adaptation to the special needs of a disabled person in learning, with understanding to perceive his position, show an active life position, get involved in integration processes. Therefore, the educational process should consider the individual as the focus of the system of social and pedagogical influence, as the initial and final points of the multifaceted process of socialization.

Communication is the basis of relationships between people, and not only people with disabilities can experience difficulties in relationships with the team. The nature of the relationship, their style, the general tone of communication depend on the psychological microclimate in which the learning process takes place. Such psy- chological and pedagogical conditions prevent the emergence of the "ugly duckling" effect when the advantage in the relationship is given to the "strong". The majority perceives students with special needs as smart, quick-witted, interested in the learning process, such as eager to help in difficult situations.

The psychological and pedagogical experience of working with students with disabilities proves that people with special needs do not feel inferior, but, on the contrary, in the conditions of university education, are revealed as individuals. There are many creative people among them, mature, able to understand others, and they quickly find friends for themselves. If a friendly and equal atmosphere has been formed in the group, the disabled person would "forget" about his or her disadvantage and stop comparing himself with others (Milner \& Kelly, 2009).

Concerning philosophy, the concept of universal design is of great importance here, which is gaining more and more relevance in the world. Need to remember - when travelling and visiting other countries of the world, more than once a large number of people with disabilities were striking, while freely moving around the city, using public transport, travelling, working and living a full life. And the point is not that there are more people abroad than in Ukraine, but there are appropriate conditions for their life and work.

There is a definite relationship between the concepts of accessibility and universal design. However, there is no reason to identify them. Universal design is a strategy, a cost-effective approach that aims to ensure that the design and components of the environment, products, communications, information technology or services are equally accessible and understandable to everyone and meet the requirements of this use.

Universal design concerns urban planning, navigation, room furnishings, service availability, and the like. In addition, it is related to schools and universities, which basically do not take into account the various possibilities 
of people.

Self Esteem of Disabled Humans

In the context of humanization and democratization of society, social and educational deformations, an important task today is to create equal opportunities for all citizens, regardless of psychophysical development, health status, age, gender, socio-economic status of a person. Therefore, the problem of realizing the personal resource of young people is gaining great importance; it faces numerous difficulties in the process of self-realization, especially of such a category as students with disabilities. Creating opportunities for successful self-realization of a person with a disability requires considering not only the factors that affect this process but, above all, the conditions necessary for the effective self-fulfilment of the person. Thus, the elucidation of the psychological conditions proper, contributing to the construction of an effective individual strategy for self-realization of disabled students, is an important task today in the context of the new educational paradigm (Mitra \& Sambamoorhi, 2006).

Effective help in achieving self-esteem for people with disabilities can be achieved through infrastructure development. Of course, in higher educational institutions, it is possible to form a certain philosophy of communication with people with disabilities, but this is not the only thing that can be done. Also, they should be given the opportunity to move and function within the university's walls on an equal basis with others.

\section{The Role of Philosophical Communication with Disabled People}

The problem of man is central to philosophy. It not only crowns the entire philosophical theory but also gives it a human-measuring meaning, evokes the worldview and value significance of philosophical culture. Man is the alpha and omega of philosophical knowledge. Each aspect of philosophical communication (comprehension of life, problems of cognition and culture, history and civilization) loaded with human meaning is the law of thinking, the reflective intellectual activity of a person (Townsend, 1985).

The most significant human resource is health since any social promotion of it is associated with stress on the body. The response to the load is the mobilization of resources (bodily, neuropsychic, etc.) and the tension of protective forces to adapt to changes and solve life problems. As you know, the body's nonspecific response to the demands presented to it is stress.

The main component of a person's behaviour in a situation of getting out of stress is search activity and communications, by which we mean activities aimed either at changing an unacceptable situation or at changing one's attitude towards it, at maintaining a favourable situation in spite of threatening factors and circumstances. Aggressive factors of the living environment of a modern person can be divided into economic, technogenic, political, social, which actualize the problem of preserving and protecting health. The preservation and protection of health are becoming more important both as an individual and as a global problem (Rosano, Mancini, \& Solipaca, 2009). Society has developed an arsenal of means of combating diseases, as well as means of protecting health, which are institutionalized thanks to the development of modern medicine, recreation, and recreation. Some institutions are building constructive, life-sustaining capacities.

The formation of society's readiness to accept people with physical disabilities into the social environment should become a state component of education, should be ensured through equal access to education, through the creation of the necessary infrastructure (architectural), through institutions of compulsory methodological training of higher school specialists to work in an integrated educational environment.

The object of the research is the buildings and structures of higher education institutions in the context of achieving social adaptation and im- 
proving communication.

\section{The Essence and Role of Socio-Adaptive Thinking}

In accordance with the possibilities and level of development, each state forms a social and economic policy to protect the rights and interests of persons with functional disabilities or mental disabilities for their socio-adaptive integration. Modern society is characterized by increased attention to the problems of people with special needs who can fully perceive, understand, and increase material and spiritual values. The formation of public opinion in need of a value-based, tolerant attitude towards this category of people is important for socially adaptive integration. Among the urgent problems of personality formation, the issues related to the integration of young people with functional limitations into modern society and, first of all, the educational environment are especially tangible and acute.

The implementation of the process of socially adaptive integration of young people with functional limitations into the social environment in social service institutions of various forms of ownership is essential both for the development of the theoretical foundations of social policy and the practical implementation of social work, assistance and support for various social groups of young disabled people. The problem of integrating young people with functional limitations is relevant and, above all, it concerns young people with sensory or motor impairments. Our society is not yet ready to accept them as equals. As a result, a contradiction arises between the need to overcome the social isolation of young people with functional limitations and the lack of appropriate psychological and socio-pedagogical conditions necessary for their life. First of all, we are talking about creating a support system that contributes to the effective social integration of this particular category of people.

\section{Methodology}

The object of the research is the buildings and structures of higher education institutions in the context of achieving social adaptation and improving communication.

The research methods are determined by the specifics of the research object and provide for a systematic approach to solving the assigned tasks, is aimed at considering the formation of the architectural environment of universities in relation to economic, social, psychological, ergonomic, environmental and aesthetic aspects, and includes examination and systematization of scientific literature, theoretical works, Internet resources on relevant issues, as well as an analysis of world and domestic experience in ensuring the technological organization of the environment of higher educational institutions, considering the nature of the human activity; graphic-analytical method of material systematization and development of schemes; conducting field surveys, collecting statistical data and analyzing them; study and generalization of modern design and construction regulations. Thus, in the research's course, the following were carried out:

1. Review and comprehensive analysis, systematization of special scientific literature, theoretical works, Internet resources, periodicals with 90 relevant issues. This analysis is necessary to identify problems, formulate hypotheses and evaluate the collected facts. The study of the literature makes it possible to find out which aspects of the problem have already been sufficiently studied, which scientific discussions are being conducted, which are outdated, and which issues have not yet been studied.

2. Analysis of the historical and modern domestic and foreign experience of improvement, design, construction and operation of the architectural environment adapted to people with disabilities.

3. Study and multidimensional analysis of ar- 
chitectural planning and volumetric spatial features of architectural and engineering solutions, methods of improving the architectural environment.

We used the IDEF0 model to improve the ways of adapting the architectural environment of higher education institutions to the needs of persons with disabilities.

\section{Research Results and \\ Discussions}

Local documents should regulate the activities of an educational organization of higher professional education for the teaching of persons with disabilities - these are provisions on the formation of an inclusive education centre (departments, services, etc.) and provisions on teaching students with disabilities. Creation of a structural unit in an educational organization of higher education, responsible for training persons with disabilities or granting appropriate powers and responsibility to existing structural units. Such a unit can be a centre (department, service, etc.) of inclusive education.

The main goal of the activity of the structural unit responsible for training people with disabilities is to create conditions for ensuring inclusive education in higher education programs. The tasks of this structural unit include pre-university training and career guidance work with applicants, support for inclusive education of students, solving issues of development and maintenance of the information and technological base of inclusive education, distance learning programs, socio-cultural rehabilitation, promoting the employment of graduates, creating a barrier-free architectural environment in the context of achieving social adaptation and improving communication.

A special section (page) should be created on the website of the educational organization, which reflects the availability of conditions for training persons with disabilities, contains training programs adapted for them, taking into account various nosologies, types and forms of training support, availability of special technical and software training aids, distance educational technologies, the presence of a barrier-free architectural environment, etc.

To improve the ways of adapting the architectural environment of higher education institutions to the needs of persons with disabilities, we applied the IDEF0 model. The block hierarchy of the functional model IDEF0 of improvements the ways of adapting the architectural environment of higher education institutions to the needs of persons with disabilities is shown in Figure. 1.

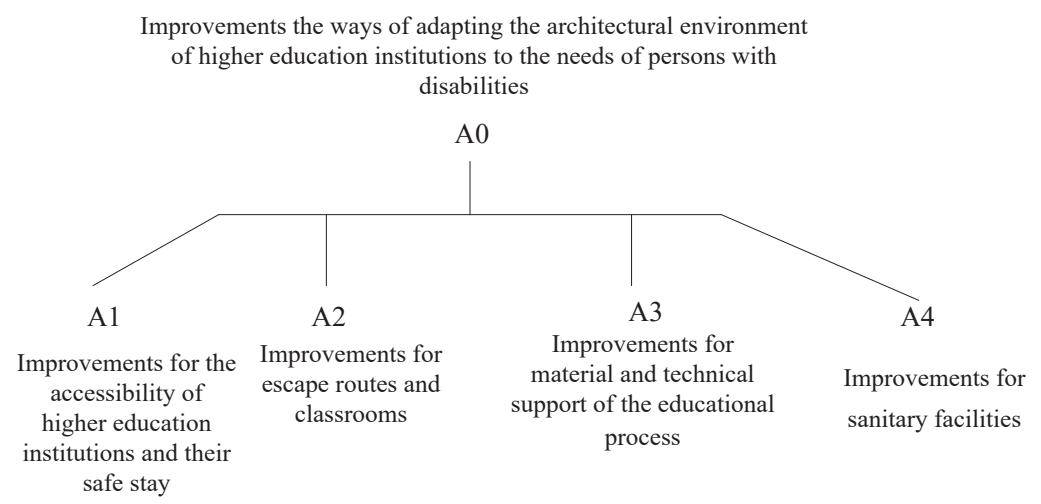

Figure 1. The block hierarchy of the functional model IDEF0 of improvements the ways of adapting the architectural environment of higher education institutions to the needs of persons with disabilities in the context of achieving social adaptation and improving communication. 
The best way to address the needs of people with disabilities is to conduct regular site surveys to ensure that accessibility requirements are met, followed by developing a strategy or program to ensure a barrier-free environment for people with disabilities. A site survey for compliance with accessibility requirements for people with disabilities is an assessment of elements of the surrounding architectural environment (buildings or sites), media systems and service delivery procedures in terms of the possibility of using them by people with disabilities, permanently or temporarily disabled, regardless of who they are (employees, visitors, etc.).

It is also a process during which existing and potential barriers to the living environment for people with limited mobility can be identified and fixed, and recommendations and proposals for improving it can be developed, which will allow those responsible for the facility under construction or operation to move to a new level of planning and implementing changes to ensure accessibility in the context of achieving social adaptation and improving communication.

\section{Conclusion}

Based on the analysis of the features of the formation of the architectural environment of higher educational institutions, it has been established that their subject-spatial environment should be formed by architectural means and ergodesign techniques, considering anthropometry and psychophysiology in the context of achieving social adaptation and improving communication. Design is based on the subjective, and ergonomics is based on the measurable, rational. Taking this into account, the design of an effective subject-spatial environment is possible with the maximum consideration of anthropometric data and psychophysiological characteristics of students with special needs.

Implementing the measures will allow in the future: to increase the level and quality of life, the level of competitiveness of people with disa- bilities in the labour market, the effectiveness of their rehabilitation by increasing the availability of social infrastructure facilities - employment, social protection, education, health care, culture and sports, as well as transport, information and communication.

To improve the ways of adapting the architectural environment of higher education institutions to the needs of persons with disabilities, we have applied the IDEF0 model in the context of achieving social adaptation and improving communication.

Research isn't limitless. We did not consider certain individual wishes or all the needs of people with disabilities. In the future, it is necessary to analyze how it is possible to architecturally improve educational institutions for very rare groups of disabilities.

\section{References}

Alrashidi, A. M. (2010). University education and students' perceptions of physical disabilities at Kuwait University. Kuwait: ProQuest Publishing.

Azeri Gorji, A. A. \& Shirzad Nazarloo, Z. (2018). Hashmandamneri iravunk'neri dirk'y k'aghak'ayin iravunk'i volortum (The position of rights of the disabled in the field of urban law, in Persian). Journal of Strategic Studies in Public Policy, 8(26), 137-163.

Boyer, E. L., \& Mitgang, L. D. (1996). Building community: A new future for architecture education and practice: A special report. Princeton: Carnegie Foundation for the Advancement of Teaching.

Carmona, M. (2010). Contemporary public space: Critique and classification, part one: Critique. Journal of Urban Design, 15(1), 123-148.

Francis, L. (2018). Understanding disability civil rights non-categorically: The Minority Body and the Americans with disabilities act. Philosophical Studies,175(5), 
1135-1149.

Froehilich, D. E., Beausaert, S. A. J., \& Segers, M. (2015). Great expectations: The relationship between future time perspective, learning from others, and employability. Vocation and Learning, 8, 213227. https://doi.org/10.1007/s12186-015-9131-6

Hallgrimsdottir, B., Wennberg, H., Svensson, H., \& Ståhl, A. (2016). Implementation of accessibility policy in municipal transport planning-progression and regression in Sweden between 2004 and 2014. Transport Policy, 49, 196-205.

Kamp, A. (2016). Engineering education in the rapidly changing World. Rethinking the vision for higher engineering education. Delft: TU Delft / 4TU Centre for Engineering Education.

Kurath, M. (2015). Architecture as a science: Boundary work and the demarcation of design knowledge from research. Science \& Technology Studies, 28, 81-100.

Lisy, K., Campbell, J. M., Tufanaru, C., Moola, S., \& Lockwood, C. (2018). The prevalence of disability among people with cancer, cardiovascular disease, chronic respiratory disease, and/or diabetes: A systematic review. International Journal of Evidence-Based Healthcare, 16(3), 154-166.

Milner, P., \& Kelly, B. (2009). Community participation and inclusion: People with disabilities defining their place. Disability \& Society, 24, 47-62

Mitra, S., \& Sambamoorhi, U. (2006). Employment of persons with disabilities: Evidence from the National Sample Survey. Economic and Political Weekly, 41, 4022-4026.

Rijst, R., Baggen, Y., \& Sjoer, E. (2018). University teachers' learning paths during technological innovation in education. International Journal for Academic Development. https://doi.org/10.1080/1360144x.2018. 1500916

Rosano, A., Mancini, F., \& Solipaca, A. (2009). Poverty in people with disabilities: Indicators from the capability approach. Social Indicators Research, 94, 75-82.

Salmela, J. (2019). Research \& Development project concerning the inclusion of students with special needs. Malmö: ProQuest Publishing.

Segrest, R. (1997). The architecture of architectural education. Assemblage, 33, 76-79. https://doi.org/10.2307/3171382

Shahraki, A. A., Ebrahimzadeh, I., \& Kashefidoost, D. (2016). Distributional planning of educational places in developing cities with case studies. Habitat International, 51, 168-177.

Simons, M., \& Masschelein, J. (2009). The public and its university: Beyond learning for civic employability? European Educational Research Journal, 8(2), 204217.

Steen, M., Manschot, M. A. J., \& de Koning, N. (2011). Benefits of co-design in service design projects. International Journal of Design, 5(2), 53-60.

Townsend, P. (1985). A sociological approach to the measurement of poverty: A rejoinder to Professor Amartya Sen. Oxford Economic Papers, 37, 659-668.

Van Dooren, E., Boshuizen, E., van Merriënboer, J., Asselbergs, T., \& van Dorst, M. (2014). Making explicit in design education: Generic elements in the design process. International Journal of Technology and Design Education, 24(1), 53-71.

Vermeersch, P., \& Heylighen, A. (2012). Blindness and multi-sensoriality in architecture. The case of Carlos Mourão Pereira. In R. Hayes, \& V. Ebbert (Eds), The place of research, the research of place. ARCC/EAAE 2010 international conference on architectural research 
(pp. 393-400) Washington DC: Architectural Research Centers Consortium (ARCC).

White, H., Saran, A., \& Kuper, H. (2018). Evidence and Gap Map of studies assessing the effectiveness of interventions for people with disabilities'. New Delhi and London: Campbell Collaboration and International Centre for Evidence and Disability.

Wirth, T., Frantzeskaki, N., Fuenschilling, L., \& Coenen, L. (2018). Impacts of urban living labs on sustainable transitions: Mechanisms and strategies for systemic change through experimentation. European Planning Studies. https://doi.org/10.1080/09654313.2018.1504895 